\title{
Las formas de la tragedia y la redención. Algunas reflexiones acerca de la idea de "derrota" de los proyectos revolucionarios en la obra de Juan Carlos Portantiero en su exilio en México (1975-1983)
}

\author{
The shapes of tragedy and redemption. Some reflexions about the idea of "defeat" of revolutionay \\ proyects in Juan Carlos Portantiero work in his exile in Mexico (1975-1983)
}

\author{
José María Casco \\ Universidad de San Martín \\ Doctor em Sociologia \\ casco.josemaria@yahoo.com.ar
}

\begin{abstract}
Resumen: El trabajo se propone indagar el modo en el cual Juan Carlos Portantiero proceso la idea de "derrota" de los proyectos revolucionario en su exilio mexicano. Más específicamente, busca dar cuenta de cuáles fueron las operaciones teóricas, conceptuales y política a través de las cuales el autor abandonó posiciones de tipo revolucionario y se abrazó en cambio, a las ideas de socialismo y democracia como los pilares fundamentales desde fines de los años 70' de sus futuros proyectos políticos e intelectuales. Para ello, el trabajo revisa su producción en forma de ensayos y trabajos académicos reconstruyendo el contexto tanto político como intelectual en el cual ese proceso tiene lugar.
\end{abstract}

Palabras-claves: Juan Carlos Portantiero, Exilio, Intelectuales

\begin{abstract}
The proposal of this work is to inquire the way in which Juan Carlos Portantiero processed the idea of "defeat" of the revolutionary proyects in his mexican nexile. More specifically, aims to show which were the theoric, conceptual and political operations from where the author abandoned revolutionary positions and, on the contrary, hugged socialism and democracy ideas as fundamental keys since ' 70 years of future political and intellectual proyects. For it, this work check his production in essays and academic work, by reconstructing the political and intellectual context in which this process take place.
\end{abstract}

Key-words: Juan Carlos Portantiero, Exile, Intellectuals 


\section{De la revolución a la democracia}

Desde mediados de la década del setenta, las políticas represivas instauradas en Argentina -ya durante el gobierno de Isabel Martínez de Perón, pero, sobre todo, con la dictadura implantada en el 76'- produjeron el exilio de muchos políticos e intelectuales. En efecto, países como Brasil, Venezuela, México, Canadá, España, Italia y Francia, fueron algunos de los destinos de un exilio que involucró además de argentinos a otros latinoamericanos que sufrían idénticas situaciones políticas.

En ese sentido el exilio representó, para muchos de esos actores del campo cultural, una doble fractura. Por un lado, produjo el alejamiento de los afectos y las rutinas cotidianas. Por otro, los condujo a un progresivo abandono de las certezas con las que se había construido el mundo fuertemente politizado de los años 60' y primeros 70'. Así, para buena parte de ellos, el nuevo estado de cosas abrió un proceso de crítica de sus posiciones políticas pero también teóricas que permitió una reelaboración tanto de las mismas, desplazando a los proyectos revolucionarios por una revalorización de la democracia.

Para poder dar cuenta de ese pasaje de uno a otro tipo de perspectiva teóricopolítica que tiene lugar en el exilio, deben tenerse en cuenta y poner en relación dos factores que, entendemos, fueron fundamentales. Por un lado, la asunción e interpretación progresiva del aplastamiento de las luchas sociales y de los grupos guerrilleros a manos de las dictaduras latinoamericanas setentistas, como una "derrota" incontestable de la estrategia revolucionaria sostenida en los años previos. Por otro, el diálogo en México con los procesos de re significación teórica y política del socialismo europeo, que aportó un marco más amplio para la reflexión de la propia "derrota "e influyo en la reflexión sobre los nuevos esquemas de interpretación y estrategias políticas que debían ser asumidas.

\section{El espacio exiliar mexicano}

Hacia mediados de la década del setenta, una serie de factores políticos, económicos y culturales contribuyeron a convertir a México en un país muy atractivo 
para los exiliados de las distintas dictaduras latinoamericanas y en un escenario favorable para el proceso de re significación del pensamiento de izquierda de la región ${ }^{1}$.

En este sentido, fue importante el proceso de democratización del modelo del PRI iniciado hacia el final del mandato de Luis Álvarez Echeverría (1970-1976) y profundizado por su sucesor, José López Portillo (1976-1982), que produjo una revitalización de la actividad política mexicana y facilitó el ingreso al país de emigrantes políticos de diversas tendencias, especialmente de izquierda. A esto se sumó un acelerado florecimiento económico-como consecuencia del "boom del petróleo" mexicano- que tuvo como correlato una "época de oro" para las universidades, con abundancia de recursos para la investigación, la publicación y el financiamiento de visitas de intelectuales extranjeros (BURGOS, 2003: 50). Así, se expandieron las instituciones de educación superior y se crearon nuevas universidades e institutos de investigación científica. Estas condiciones fueron altamente productivas ya que, entre otros factores, posibilitaron que México se convirtiera en

Caja de resonancia y lugar privilegiado de observación, estudio y discusión de los procesos en marcha en las sociedades latinoamericanas y, sus universidades e institutos de investigación, en espacios frecuentados por una pléyade de intelectuales vinculados a la izquierda de las diversas variantes [...] Por las mismas razones, México desempeñó un lugar destacado en la publicación de textos vinculados a la cultura socialista y al marxismo en particular (BURGOS, 2003: 231).

Por último, el crecimiento de la economía fue acompañado, también, por una ampliación del aparato estatal que pasó a asumir nuevas responsabilidades en la promoción de proyectos de desarrollo económico y social y políticas culturales (YANKELEVICH y JENSEN, 2007). El conjunto de estos factores favoreció una amplia inserción laboral de los intelectuales y académicos exiliados en dependencias gubernamentales (CASTAÑEDA, 1989) y en instituciones académicas. ${ }^{2}$

\footnotetext{
${ }^{1} \mathrm{Si}$ bien existen dificultades para establecer la cifra exacta de exiliados en México durante el período estudiado, según Margulis (1986) hacia 1980 había entre 5000 y 7500 argentinos. Como sea, cabe destacar que México ya detentaba para entonces una larga historia como país de refugio, legalizada en su Carta Magna con el derecho de asilo desde los albores del siglo XX.

${ }^{2}$ Las universidades, entre las que se destacaron la Universidad Nacional Autónoma de México (UNAM), la Universidad Autónoma Metropolitana (UAM) y el Instituto Politécnico Nacional (IPN), fueron
} 
También fueron de vital importancia para la contención de los emigrados al espacio mexicano, las instituciones creadas como respuesta a la nueva situación. Entre las más significativas de origen argentino, la primera en aparecer fue la Comisión Argentina de Solidaridad (CAS), fundada a comienzos de 1975 por un grupo compuesto por peronistas camporistas y militantes de izquierda distanciados de sus organizaciones políticas $^{3}$. Hacia octubre del mismo año, como un desprendimiento de CAS, surge el Comité de Solidaridad con el Pueblo Argentino (COSPA) por iniciativa de miembros de Montoneros y del trotskista Partido Revolucionario de los Trabajadores (PRT) Ambos agrupamientos se vincularon con las comunidades de expatriados argentinos y latinoamericanos emplazadas fuera de México, conformando una red de lucha contra los regímenes dictatoriales de América Latina. Así, el exilio de México estrechó lazos con los exiliados radicados en España, Francia, Venezuela, Costa Rica y EEUU. Esto facilitó el intercambio de información y también creó condiciones para que las actividades se difundieran más allá de los países involucrados.

Entre los objetivos inmediatos de CAS y COSPA estuvo, además de la denuncia de la dictadura argentina ${ }^{4}$, la acogida y contención de los recién llegados, ayudando a estos en la trámites de radicación, en la obtención de una vivienda o un empleo, etc. ${ }^{56}$. Pero por sobre todo, dichas instituciones desempeñaron un papel de gran relevancia como espacios de sociabilidad y de encuentro para los emigrados. A través de la organización de reuniones y eventos de carácter político, cultural y social (asados, peñas, proyección de películas, obras de teatro, presentación de libros, etc.) sentaron las bases para la conformación de una suerte de micro sociedad en esa comunidad de

centrales en el desarrollo de las actividades de docencia e investigación de muchos de los expatriados (BERNETTI y GIARDINELLI, 2003:29-30).

${ }^{3}$ Su primer Secretario General fue el ex gobernador de Córdoba, Ricardo Obregón Cano, reemplazado dos años más tarde por Rodolfo Puiggrós, hecho que hizo posible que a la CAS se la denominara también la "Casa de Puiggrós", debido a la relevancia de su figura. El núcleo originario congregó también, entre otros, a Esteban Righi, HaydeéBirgin, Rafael Pérez, Noé Jitrik y Tununa Mercado.

${ }^{4} \mathrm{La}$ denuncia de la represión y de la violación a los derechos humanos tuvo varios canales de comunicación. Uno de ellos fue la difusión de la información a través de revistas y solicitadas, con testimonios de las víctimas. También, a través de conferencias, actos públicos, asambleas y eventos de diverso tipo.

${ }^{5}$ En CAS funcionaba una suerte de Oficina Migratoria y una Bolsa de Trabajo. En COSPA, un hotel, un restaurante y una guardería infantil.

${ }^{6}$ También se crea la Coordinadora de Derechos Humanos (CDDHH) que utilizaba, alternativamente, los locales de CAS y COSPA. El eje de su actuación estuvo puesto en la denuncia de la represión y el reclamo por los detenidos y desaparecidos. Dado lo específico de sus objetivos, integró a representantes de distintas organizaciones de DDHH, lo que muchas veces le quitó eficacia a la hora de tomar decisiones. Las más importantes fueron la Comisión Argentina de Derechos Humanos (CADHU) y la Comisión de Familiares de Presos, Muertos y Desaparecidos por razones políticas en Argentina (COSOFAM)Los principales referentes de la Coordinadora de DDHH fueron el abogado Carlos González Gartland (CADHU) y Susana Míguez (COSOFAM). 
exiliados, que no sólo incluyó a argentinos sino también a otros latinoamericanos radicados en México. En ese espacio de circulación, como veremos más adelante, los expatriados -especialmente, intelectuales y académicos- encontraron un ámbito propicio para llevar adelante una tarea de reflexión y discusión, no exenta de tensiones y rupturas, sobre la nueva situación latinoamericana generada a partir de la implantación de los regímenes autoritarios que los habían llevado al exilio.

\section{La emergencia del debate sobre la democracia en el marco regional latinoamericano: el rol de las instituciones académicas}

Una parte importante de la discusión y difusión de los nuevos paradigmas que como veremos- asume la intelectualidad de izquierda exiliada en México, tuvo lugar en seminarios, jornadas y coloquios realizados entre 1978 y 1980 en distintos lugares de América Latina. Promovidos por universidades y centros de investigación mexicanos o por el Consejo Latinoamericano de Ciencias Sociales (CLACSO), el conjunto de estas reuniones fue altamente productivo para el intercambio y el debate de ideas entre intelectuales de diversas tendencias teóricas que reflexionaron sobre algunas problemáticas como el autoritarismo, la democracia, el papel de la izquierda, y las nuevas orientaciones teóricas y políticas del socialismo europeo. Si bien algunos trabajos presentados analizaron situaciones nacionales, contribuyeron de todos modos a poner el marco de las nuevas perspectivas y preocupaciones que iban ganado el centro del campo intelectual y académico latinoamericano.

Así en octubre de 1978 se realizó en Costa Rica, a iniciativas de CLACSO, la primera conferencia regional "Las condiciones sociales de la democracia"7 . Este fue el punto de partida de una serie de encuentros que buscaban reunir reflexiones de intelectuales de diferentes tendencias teóricas sobre los caminos posibles para una salida al autoritarismo. Un año más tarde, en Río de Janeiro se celebró la segunda conferencia regional "Estrategias de Desarrollo Económico y Procesos de Democratización en América Latina”, también organizada por CLACSO. Por su aporte a la recuperación del concepto de democracia para el pensamiento de izquierda, fue importante también el seminario realizado en Morelia (Michoacán) en el mismo año que, organizado por el Instituto de Investigaciones Sociales de la UNAM, estuvo dedicado a la discusión del

\footnotetext{
${ }^{7}$ El material del ese primer encuentro fue reproducido por la revista Critica y Utopía en sus primeros cuatro números.
} 
concepto de hegemonía ${ }^{8}$. En 1981, tuvo lugar en Caracas la conferencia regional "Estrategias para el fortalecimiento de la sociedad civil", preparada por el Centro de Estudios para el Desarrollo de esa ciudad (LESGART, 2003:72,74).

Asimismo, cabe destacar que, más allá de la organización de las conferencias mencionadas, la actividad de CLACSO fue central para el desarrollo del trabajo intelectual de los exiliados en distintos países de América Latina.

Creada en 1967, esta institución tuvo como objetivos centrales el fortalecimiento de las ciencias sociales en América Latina y el establecimiento de vínculos académicos regionales. En las asambleas que se llevaron a cabo en noviembre de 1973 y marzo de 1974, en las ciudades de Río de Janeiro y Maracaibo respectivamente, se dispuso, como respuesta a la situación creada por las dictaduras instauradas en Chile y Uruguay, un programa de solidaridad y defensa de los científicos sociales de la región que fueran víctimas de la represión académica. A tales fines, por ejemplo, se instrumentó una bolsa de becas que favoreció ampliamente el intercambio académico y la circulación y comunicación entre los intelectuales latinoamericanos. Asimismo, el organismo reunió a los centros de estudio más importantes de la región, promovió publicaciones y desarrolló grupos de discusión y trabajo que abordaron distintas problemáticas de interés regional. Entre ellos, el más sobresaliente para lo que aquí importa, fue el grupo de estudios sobre Estado y Política, coordinado por Guillermo O’ Donnell primero y, luego, por NorbertLechner, puesto que por ese espacio, en efecto, pasó buena parte de la discusión sobre el autoritarismo y la democracia. ${ }^{9}$

\section{La construcción de los nuevos paradigmas de izquierda. El socialismo y la democracia como horizonte y como problema}

Desde muy temprano, conforme llegaban a México noticias sobre el avance de la represión en diferentes lugares, fueron ganando predominio entre los exiliados

\footnotetext{
${ }^{8}$ Los trabajos presentados en el seminario fueron compilados por Julio Labastida en el libro Hegemonía y alternativas políticas en América Latina, con prólogo de José Aricó. Allí el prologuista destacaba la importancia del concepto de hegemonía como una herramienta teórico-política que podía condensar la heterogeneidad social sin caer en el reduccionismo de la perspectiva de clases. Volveremos sobre el tema más adelante, pero dejemos anotado que aquí se destaca un desplazamiento en la perspectiva adoptada por Aricó (1985: 05).

${ }^{9}$ Producto de esa experiencia se publicaron dos libros compilados por Lechner que recogían trabajos que eran el fruto de las reuniones, Estado y Política en América Latina (1981) y El debate teórico sobre la democracia ¿Qué significa hacer Política? (1982)
} 
pertenecientes a las distintas versiones de la izquierda latinoamericana ${ }^{10}$, visiones que interpretaban el fenómeno como la demostración práctica de la inviabilidad de la estrategia revolucionaria para llevar adelante el cambio social. La idea de una "derrota" político-militar y teórica -ya que ponía en cuestión hasta los mismos fundamentos con que se había interpretaba el mundo y las vías de su transformación hasta el momento- se colocaron como una respuesta a la perplejidad y el desconcierto que causaba la magnitud de la represión. Esto debido a que no sólo las organizaciones guerrilleras habían sido aniquiladas, sino que, de acuerdo con muchos de esos exiliados, el completo campo popular había quedado diezmado ${ }^{11}$. En ese sentido, quizás quien mostró de manera más contundente la sensación de una pérdida irreparable fue el sociólogo peruano Aníbal Quijano:

Esa derrota fue la mayor a lo largo de cinco siglos. En los últimos 500 años, a medida que la historia fue transcurriendo, parecía haber un horizonte brillante con muchos nombres: progreso, identidad, liberalismo, nacionalismo, socialismo. Las derrotas siempre fueron coyunturales. Hubo muchas derrotas, pero también muchos éxitos [...] Con la última derrota no solamente fueron derrotados los regímenes políticos; movimientos, organizaciones, discursos, por primera vez, todo ese horizonte naufragó. Esto explica la facilidad con que surgió y se diseminó un pensamiento único, como un sentido común para todo el mundo. Incluso para personas más resistentes o, tal vez, más lúcidas, fue un período de aislamiento terrible. Casi súbitamente, lo que las personas esperaban y que consideraban posible, quedó como un discurso del pasado, y de un pasado remoto (ApudSOARES, 2003: 260).

La progresiva desafiliación de una parte de los exiliados respecto de las ideas revolucionarias, tuvo como correlato un reacomodamiento de los grupos que integraban la comunidad argentina. Las primeras disidencias ya se habían manifestado tempranamente cuando los sectores más radicalizados -Montoneros y PRT-

\footnotetext{
${ }^{10}$ Esto involucro entre los argentinos a diferentes extracciones ideológicas tanto socialistas en sus diferentes versiones, como también a la izquierda de extracción peronistas.

${ }^{11}$ Todos los viernes llegaban al DF Mexicano los ejemplares de la semana de los diarios La Razón, La Nación y Clarín al local de la CAS. Con las noticias de los "subversivos muertos en enfrentamientos" según el testimonio de Portantiero y Bufano. Y por ello al decir de éste último no había con qué reorganizar un espacio de izquierda en los términos que se habían dado en los años 60'. Entrevistas con el autor. Octubre y julio de 2005 respectivamente.
} 
abandonaron CAS para fundar COSPA en octubre de 1975. COSPA se había convertido en un principio, en la organización más significativa con el mayor número de adherentes. Sin embargo, con el transcurso del tiempo, y a medida que fueron cobrando fuerza las nuevas posiciones, se modificó la composición y representatividad de las dos instituciones. COSPA, cuya cúpula dirigente se mantuvo durante todo el período férreamente anclada en la convicción de la lucha armada y la vía revolucionaria, sufrió una importante sangría en el número de sus miembros y fue perdiendo protagonismo a favor de CAS, en la que, en cambio, dominaron desde el comienzo sectores que sostenían el carácter equívoco y la caducidad de dichos métodos.

En COSPA dirimieron sus internas los Montoneros, pero si bien no estuvieron exentos de querellas, hay que decir que en conjunto durante un largo tiempo vieron al exilio como formando parte de un repliegue estratégico, donde la contraofensiva se explicaba en esa dirección. El hecho, asimismo, de que una figura como Rodolfo Puiggrós haya sostenido hasta el final de sus días la estrategia montonerista, le dio a las tesis que sostenían la posibilidad de una contraofensiva un halo de autoridad en donde podían ampararse. En la misma tesitura podría ubicarse el análisis del PRT-ERP. En efecto, si bien tampoco estuvo exento de luchas y fracturas internas como lo muestra el desprendimiento en dos fracciones una liderada por Mattini mas volcada hacia la construcción de un partido que abandona la lucha militar y otro, liderado por Gorriaran Merlo, que se incorpora a la lucha sandinista que se libraba en Centro América, el exilio mexicano fue la base y un laboratorio para la continuidad de las expresiones revolucionarias $^{12}$.

Como sea, Hacia 1977, la partida de un grupo de intelectuales de extracción peronista, integrado por Héctor Schmucler, Sergio Caletti, Carlos Ávalos, Jorge Bernetti y Nicolás Casullo, señaló uno de los más importantes desprendimientos que experimentó $\operatorname{COSPA}^{13}$. Estos se incorporaron a CAS y conformaron un grupo crítico del ideario político-militar guerrillero peronista y marxista, conocido dentro de la

\footnotetext{
${ }^{12}$ Para un análisis de la trayectoria de Montoneros en México, sus disputas, posiciones y rupturas véase Confino (2018 y 2019) Para un análisis de la actuación de Puiggrós en su exilio mexicano Acha ( 2006) Para un análisis del PRT ERP, sus disputas y reacomodamientos en el exilioCarnovale (2014) Para una memoria y balance de exiliados que abandonaron posiciones de tipo revolucionaria véase Ollier ( 2009)

${ }^{13}$ Uno de los temas más polémicos que llevaron a la ruptura del grupo con COSPA fue la posición asumida frente a la represión. El órgano de prensa de Montoneros sostenía que hacer hincapié en la aniquilación, el exilio y el encarcelamiento sufridos por las víctimas de la represión de estado, constituía una postura derrotista que le hacía el juego al enemigo. Esto era contestado desde el otro lado como una demostración del dogmatismo de la organización. Alrededor de ese tema giraron gran parte de las discusiones que se expresaron tanto en los órganos de prensa de las diversas agrupaciones como en diarios de tirada nacional.
} 
colonia argentina como el "Grupo de los Reflexivos" (DE DIEGO, 2003:159). Y fue en CAS precisamente donde se desarrollaron los primeros encuentros de intelectuales partidarios de una perspectiva social democrática. En esa dirección allí a partir de 1979, comenzó a funcionar la Mesa de Discusión Socialista que incluyó, entre otros, a José Aricó, Oscar Terán, Jorge Tula, Carlos Ávalos, Liliana De Riz, Sergio Bufano, Osvaldo Pisano, Ricardo Nudelman, Osvaldo Pedroso, Oscar del Barco, Emilio De Ipola y Juan Carlos Portantiero en la que también participaron militantes de la Confederación Socialista Argentina y del Partido Socialista Popular. El grupo se reunió de manera mensual hasta 1982 para reflexionar sobre la nueva coyuntura latinoamericana y pensar la adecuación de las herramientas tanto teóricas como políticas de un nuevo socialismo como posible vía de salida al autoritarismo. Así, institucionalizó la crítica del marxismo como punto de partida de una reformulación de su práctica política. A fines de 1979, buena parte de quienes integraban la mesa, junto a miembros del "Grupo de los Reflexivos", comenzó a editar la revista, Controversia. Para el análisis de la realidad argentina. ${ }^{14}$ La publicación se convirtió en el escenario de discusión más importante de intelectuales argentinos en el exilio ${ }^{15}$.

En su primer editorial, se presentaba a la revista como una consecuencia necesaria de "un nuevo estado de ánimo" que comenzaba a surgir en una parte de los exiliados argentinos, y que se manifestaba como la necesidad de "convertir este exilio en una experiencia positiva”. Así, se proponía como objetivo no sólo informar sobre la situación del país, sino también realizar una "severa pero lúcida reflexión”que buscaba "reflexionar críticamente sobre temascentrales para la reconstrucción de una teoría política que pueda dar cuenta de una transformación sustancial de nuestro país" (BURGOS, 2004: 285). El toque de reunión lo constituyó el reconocimiento de la “derrota" de los proyectos revolucionarios. Allí, decían sus protagonistas, se situaba el

\footnotetext{
${ }^{14}$ La iniciativa de hacer la publicación fue de Miguel Ángel "el gordo" Picatto de acuerdo con el testimonio de Portantiero. Este periodista cordobés en una de las tantas cenas que el contingente de exiliados de la CAS realizaba semanalmente, sugirió que las discusiones acerca de la coyuntura que se llevaba adelante debía plasmarse en una publicación y abrirse a todas las voces que quisieran debatir sobre la realidad argentina. Por desaveniencias en el formato, Picatto finalmente no fue de la partida pero sembró la semilla para una nueva institución cultural de los intelectuales argentinos radicados en México que a la postre resultó ser la reflexión teórica más importante de esos años de exilio.

${ }^{15}$ La dirección de la revista estuvo a cargo de Jorge Tula. Su secretario de redacción fue Osvaldo Pedroso. El consejo de redacción estuvo formado por Sergio Bufano, Carlos Ávalo, José Aricó, Ricardo Nudelman, Rubén Caletti, Nicolás Casullo, Oscar Terán, Juan Carlos Portantiero y Héctor Schmucler. Como articulistas invitados participaron Oscar del Barco, Jorge Bernetti, Adriana Puigróss y Emilio de Ípola, entre otros. Para un análisis sistemático de la revista véase (Gago, 2012) Para un análisis que puntualiza algunos debates (Farías, 2013, 2014) Para un análisis comparativo con respecto a La Ciudad Futura que tuviera a muchos de estos intelectuales como animadores véase (REANO, 2013, 2014).
} 
punto de partida para una reflexión crítica y superadora de las posiciones políticas y teóricas que se habían sostenido. Esto es, que la revista venía a consumar un desplazamiento teórico y político y así cerrar el capítulo de la nueva izquierda. De ahí que el editorial del primer número sentenciara:

Muchos de nosotros pensamos, y lo decimos, que sufrimos una derrota, una derrota atroz. Derrota que no sólo es la consecuencia de la superioridad del enemigo, sino de nuestra propia incapacidad para valorarlo, de la sobrevaloración de nuestras fuerzas, de nuestra manera de entender el país, de nuestra concepción de la política. Y es posible pensar que la recomposición de esas fuerzas, por ahora derrotadas, será tarea imposible si pretendemos seguir transitando el camino de siempre, si no alcanzamos a comprender que es necesario discutir incluso aquellos supuestos que creemos adquiridos de una vez para siempre para una teoría y práctica radicalmente transformadora de nuestra sociedad (CONTROVERSIA, 1979:02).

De modo contundente se planteaba que era necesario volver a pensar todo, teoría y práctica, eso hacía necesario poner el foco de atención en todo lo actuado, la revista servirá, en ese sentido como vehículo de una reflexión histórica y teórica de envergadura. De ahí que el marxismo y los regímenes socialistas de Europa del este fueran algunos de los focos de análisis que recorrieron sus 13 números ${ }^{16}$.

En esa dirección y a través del examen de varios tópicos caros a la política $\operatorname{argentina}^{17}$, fue ganando terreno la idea de que la salida al autoritarismo sólo podía llevarse a cabo mediante la recuperación de la democracia como salvaguarda de los derechos elementales para la vida, esto se asociaba íntimamente a la campaña que en

\footnotetext{
${ }^{16}$ Esto no significa desconocer, para el estudio de los debates producidos en la época en torno a los temas del socialismo y la democracia, la importancia de otras publicaciones latinoamericanas. Así, deben mencionarse Crítica y Utopía, la Revista Mexicana de Sociología, Socialismo y Participación y Nexos. En Europa, Zona de España y Plural de Alemania cumplieron el mismo papel. En otro plano, los Cuadernos de Pasado y Presente y la colección de la Biblioteca de Cultura Socialista de la Editorial Siglo XXI, a cargo de José Aricó, contribuyeron al debate dentro del campo de la izquierda y a la recolocación de autores antes ignorados. En esa clave deben entenderse las ediciones de los libros de Carl Schmitt y Max Weber, sobre las que volveremos más adelante, que ensanchaban la perspectiva para el análisis de la problemática política argentina y latinoamericana.

${ }^{17}$ Temas como la relación Estado - sociedad civil, el papel de las diferentes culturas política argentina, la función de las corporaciones y los grupos de presión, el papel de la guerrilla, el peronismo y la clase obrera, la relación peronismo y democracia, entre otros, fueron sometidos a examen a través de polémicas, Dossiers, artículos seriados y cartas de lectores.
} 
otro orden se libraba por los derechos humanos desde sus organismos específicos. Así, cobró fuerza la premisa que el Estado de derecho y las libertades civiles y políticas consagradas por la democracia liberal, debían ser revalorizadas y asimiladas como elementos esenciales en la agenda de la izquierda latinoamericana. Esta tarea supuso el examen de cuál había sido el papel otorgado a la democracia política en el ideario socialista, buscando desarticular tanto las versiones más duras, que la señalaban como una "máscara burguesa", como las más moderadas, para las que apenas era un "instrumento" en el pasaje al socialismo. Asimismo, era necesario desbaratar la imagen clásica -compartida tanto por socialistas como por liberales- que colocaba al régimen democrático como patrimonio de la tradición del liberalismo político.

En esa dirección, el intelectual mexicano Carlos Pereyra afirmaba, que la relación entre democracia y socialismo había estado llena de equívocos en la doctrina socialista. Entre los más importantes señalaba la creencia acerca de que la lucha por la democracia y sus logros era obra de la burguesía y por otro lado, la consideración fuerte en la tradición socialista de que la abolición de la propiedad privada encerraba, en sí misma, la realización de la democracia social, volviendo inútil, para la izquierda, el señalamiento explícito de metas relacionadas con la democracia política (DEVES VALDEZ, 2002: 301).

Esta segunda cuestión fue abordada con gran interés por el grupo de socialistas que integraba Controversia... que, tomando como referencia las experiencias del socialismo real, puso en cuestión que la democracia fuera co extensiva al socialismo, y se esforzó por señalar el carácter autoritario de todo marxismo que soslayara el respeto del Estado de derecho y de las garantías y libertades civiles y políticas. Así, en el acta de constitución de la Mesa de Discusión Socialista se señalaba la necesidad de examinar profundamente " $[. .$.$] los fenómenos de autoritarismo y burocratización presentes en las$ sociedades socialistas" a través de un "[...] reexamen crítico de las teorías y de las prácticas socialistas [...]”" (BERNETTI y GIARDINELLI, 2003: 29,30). Por su parte, en el primer editorial de Controversia... se reafirmaba esta posición sosteniendo que el "socialismo real" ha puesto en cuestión el significado mismo del socialismo [...] y que

[...] es preciso abandonar retórica y moralismo para abordar serenamente los efectos de una crisis de la teoría y de la práctica del movimiento socialista. Porque es difícil de sostener que la fenomenológica concreta de las sociedades post revolucionarias, con sus acentuados rasgos autoritarios y 
burocráticos, no cuestiona directamente el pensamiento marxista (CONTROVERSIA, 1979: 04).

De manera similar, Oscar del Barco se refería al fracaso de la Revolución Rusa en un libro que, quizás, es el que mejor resume este ajuste de cuentas de los intelectuales de izquierda argentinos con el marxismo. En Esbozo de una crítica a la teoría y práctica leninista (1980), señalaba que "los principios de auto liberación, autogestión, democracia y libertad absoluta que fundan la posibilidad del socialismo como tal, habían sido dejados de lado en la etapa pos revolucionaria" (DEL BARCO, 1980:05). Con esta contundente afirmación como punto de partida, el autor recorría en su texto las razones de ese abandono analizando tanto la teoría como la práctica leninistas, para terminar sosteniendo en líneas generales que todos esos desvíos que señalaba estaban en la raíz de la doctrina de Lenin ${ }^{18}$. Por su parte, Oscar Terán, se sumaba de algún modo a la crítica de Del Barco hecha al régimen soviético en un artículo publicado en Controversia... donde expresaba: "Una doctrina con elementos libertarios y antiestatalistas debería explicar [...] de qué modo las promesas que anunciaban el fin de la prehistoria han podido reforzar la historia de crímenes y tormentos de un siglo que no ha carecido precisamente de horrores" (TERAN, 1980:18,22).

Es decir que podía igualarse al nazismo y al estalinismo en tanto regímenes autoritarios y criminales. Así, esta relectura del marxismo-leninismo a la luz de una condena de los modelos socialistas de la URSS y Europa del este, junto con los otros factores señalados -la asunción de la "derrota" y la re significación de la democracia dentro del ideario socialista- confluyeron en la construcción de un nuevo paradigma teórico-político de tipo socialdemócrata. Para la fracción de intelectuales a que hacemos referencia, la defensa de la libertad individual y del pluralismo en tanto expresión de la libertad colectiva se convirtió en un valor político fundamental. Libertad que sólo podía ser garantizada a través de la vigencia del Estado de derecho y de la democracia

\footnotetext{
${ }^{18}$ El libro suscitó una fuerte polémica dentro del grupo no exenta de discusiones subidas de tono. Lo que se le reprochaba a Del Barco era atribuirle a las concepciones de Lenin ser la fuente principal de las prácticas del estalinismo. Las discusiones al parecer, revelan bien el hecho de que la autocrítica no solo no era homogénea sino que para algunos no cualquier límite podía ser traspasado. Entrevista con Osvaldo Pedroso. Julio de 2007.
} 
política, entendidos, asimismo, como prerrequisitos indispensables para la construcción futura del socialismo.

Ese fue el núcleo de la reformulación de la tradición socialista llevada adelante por la intelectualidad de izquierda exiliada en México que se nucleaba alrededor de la revista Pasado y Presente. Como señalamos, fue fruto de un trabajo que involucró a una parte importante del campo intelectual y académico latinoamericano de la época, en el que se entabló un diálogo y debate permanente en torno de estos temas.

No obstante, es preciso señalar que esta reelaboración del pensamiento de izquierda latinoamericano no puede entenderse sino a condición de atender al proceso de reconfiguración que se estaban produciendo en el espacio de la izquierda política, intelectual y cultural de los países latinos de Europa desde fines de los años setenta. En efecto, el proceso que se conoce como la "crisis del marxismo"19 funcionó como una suerte de espejo mostrando cómo el dinámico campo socialista funcionaba como un permanente diálogo acerca de qué posiciones tomar para una avanzada al centro de la escena político en uno y otro lado del Atlántico. ${ }^{20}$

\section{La crisisdel marxismo en el debate europeo}

La discusión en el campo socialista que se conoció como la "crisis del marxismo" a mediados de los años 70' tuvo su epicentro en España, Italia y Francia cuando, después de haber sido durante mucho tiempo su paradigma hegemónico y haber tenido una época de oro en el decenio que va de 1968 a 1978, el marxismo entró en decadencia como ideología política y modelo teórico para gran parte de la izquierda. Esto fue el producto, de varios factores, por una parte, de la desaparición de las figuras más relevantes del marxismo de esas naciones (la muerte de Poulantzas y DellaVolpe y el declive personal de Althusser) ${ }^{21}$ por otra, del ascenso de los llamados nuevos

\footnotetext{
${ }^{19}$ No debemos dejar de mencionar que la llamada "crisis del marxismo" reconoce una vigorosa tradición que se remonta al siglo XIX con el famoso y pionero "Bernstein Debat". Sin embargo, lo que otorga singularidad a este capítulo de esa crisis, es el hecho de que hacia fines de los años setenta la misma dio como resultado el advenimiento de una corriente caracterizada como "pos marxista", en algunos casos y, en otros, el abandono definitivo de esa tradición intelectual.

${ }^{20}$ El punto ya ha sido señalado en Lesgart (2003) y Burgos (2004) Sin embargo creemos que debe ser profundizado a fin de mostrar un cuadro más complejo que establezca las relaciones entre el campo intelectual que se expresa en el exilio y el campo intelectual europeo.

${ }^{21}$ Después de los sucesos de mayo del 68' en Francia, Althusser se transformó en el filósofo oficial del marxismo latino y su prestigio se expandió por toda Europa durante la siguiente década. Galvano DellaVolpe, de la misma manera, se convirtió en un referente importantísimo en la Italia de posguerra y
} 
filósofos, en Francia en reemplazo de los viejos maestros, entre los que se destacaron André Glucksmann (discípulo predilecto de Althusser, hecho que le otorgó cierta legitimidad de origen a sus intervenciones) y Henri Lèvy. Estos nuevos filósofos ocuparon por un tiempo el centro de la escena y proclamaron el carácter intrínsecamente totalitario del marxismo por tratarse, en el terreno de la teoría, de una doctrina omnicomprensiva de lo social que anulaba las diferencias y, en la práctica, por haber degenerado en un tipo de Estado autoritario como el soviético. También fue importante en el proceso de declive del marxismo, la emergencia de una corriente revisionista que examino al pensamiento marxista del siglo $\mathrm{XX}$, poniendo en cuestión las tendencias teóricas que se expresaron en la II y III Internacional para culminar en la crítica a las obras de Lenin la figura más importante del marxismo pero también a las de Marx, Engels.

Dentro de ese movimiento revisionista desempeñaron un papel fundamental intelectuales de prestigio como Norberto Bobbio, Christine Buci-Glusckmann, Giacomo Marramao, Gianfranco Poggi, Humberto Cerroni y Lucio Coletti. Bajo el auspicio de una red de fundaciones que promovieron la realización de seminarios, encuentros de discusión, coloquios y la publicación de libros, entre las que sobresalieron Basso Issoco y Enaudi dedicadas a promover un socialismo de tipo democrático. Estos intelectuales se proponían contribuir a la construcción de una nueva izquierda en Europa que se alejara definitivamente del canon soviético. Así, en el plano político, veían ejemplificada ese proyecto en la experiencia del Eurocomunismo, conformado por los PC italiano, francés y español, y que apuntaba a la vía parlamentaria y democrática para llegar al poder en reemplazo de la estrategia de asalto al Estado ${ }^{22}$. Esta razón de índole político estaba en parte en el origen de todo el trabajo crítico. En efecto, el examen del corpus marxista tuvo como objetivo principal, confrontar a la luz del desarrollo histórico el canon del marxismo de manera de poder encontrar los argumentos que

Nicos Poulantzas, a partir de su estadía en Paris, pudo construir una posición significativa ocupándose de la cuestión del Estado en sus investigaciones Paramio (1987).

${ }^{22}$ Si bien es extensa la bibliografía sobre el tema, a modo de ejemplo podemos nombrar: 1) La crisis del capitalismo en los años veinte de Giacomo Marramao et. al.(1981) El volumen recopilaba las ponencias presentadas en el seminario sobre "La tercera internacional y el destino del capitalismo en los años veinte" patrocinado por la fundación Basso-Issoco en 1976; 2) La terza internazionale e il partito Comunista de Ernesto Ragioneri compilador (1978); 3) Il partito nel sistema soviético 1917-1945 de Giulano Procacci (1975); 4) el trabajo de Franco de Felice sobre el VII Congreso de de la Tercera Internacional Fascismo, democracia, fronte populare (1974); 5) El desarrollo del Estado moderno de Gianfranco Poggi (1978) y Encuentro con Max Weber del mismo autor (1981). 6). Por el lado de los españoles no debe dejar de mencionarse el influyente libro de Fernando Claudín Eurocomunismo y socialismo (1977). 
hicieran posible una salida para pensar la política en el marco de un programa de relanzamiento de la izquierda al centro de la escena política europea. En términos generales, ese examen arrojó como resultado la idea de que en el marxismo salvo excepciones entre las que se contaba Gramsci, no había elementos de una teoría consistente de la política y del Estado, sino que, por el contrario, el análisis del modo de producción capitalista era el objeto privilegiado, agotándose allí los temas nodales del marxismo.

Cuando ese análisis se abocó a la obra de Marx, fue Norberto Bobbio quien disparó la polémica con otros intelectuales al expresar, de modo contundente, la ausencia de una teoría de la política en la obra del autor del Capital. Respecto de Lenin, erigido en el exponente central del socialismo desde los primeros años del siglo XX, el resultado no fue mejor. No se encontraba en su obra una indagación fructífera sobre las funciones y el desempeño del Estado capitalista. Esta interpretación se reforzaba por el hecho de que lo se había proyectado, en las pocas referencias que se encontraban en los autores clásicos, como un Estado de transición hacia el socialismo, a principios de los setenta, lejos de extinguirse, se había erigido en un gigante burocrático con gran presencia en la sociedad, tanto en las sociedades capitalistas como en las socialistas.

Asimismo, en una reunión llevada a cabo en Venecia en noviembre de 1977 por diferentes intelectuales de la izquierda continental, Louis Althusser sostuvo que no hay en Marx una teoría del Estado. Tiempo después los italianos nucleados alrededor de la revista IL manifesto, le propusieron al filósofo francés un intercambio más profundo. Un año después ese diálogo se cristalizó en el volumen discutir el Estado. Posiciones frente a una tesis de Louis Althusser, que recogía el amplio debate suscitado entre el francés y los intelectuales italianos. Allí se puntualizaban críticas a las posiciones del francés pero en términos generales todos los participantes del debate testificaban su tesis central admitiendo la carencia de una vasta teoría general de la política y el Estado en el corpus marxista. En ese sentido y como conclusión Bobbio sostendrá que el principal escollo que arrojaba ese balance estaba dado por el hecho de que la teoría marxista, al centrarse en la problemática de quién gobierna desde una dimensión instrumentalista, había descuidado el problema de cómo se gobierna, desatendiendo a la cuestión de las estructuras institucionales. Abriendo así el camino para que liberalismo y socialismo pudieran encontrarse. $\mathrm{Y}$ en lo que hace al plano teórico del debate y a propósito del saldo que este dejaba, los revisionistas proponían la incorporación de teorías que atendieran al funcionamiento capitalista y al desarrollo estatal. Y ahí 
aparecía como un punto privilegiado el nombre de Max Weber puesto que introducía elementos para pensar la política allí donde el marxismo dejaba "un punto ciego". Eso fue lo que hizo posible el redescubrimiento de su obra política. Fue Gianfranco Poggi en ese sentido, quien, en dos libros; Encuentro con Max Weber (1979) y El desarrollo del Estado Moderno (1978) resumió esa articulación entre el comunismo italiano y el pensador alemán. En el segundo de ellos, Poggi, afirmaba que la tendencia de muchos marxistas a considerar "las estructuras políticas sólo desde el punto de vista de la "critica de la economía política" tuvo algunas desafortunadas consecuencias pragmáticas para los movimientos políticos que recurren a Marx como su principal inspiración" (16), señalando nuevamente la falencia de una teoría política en la tradición del marxismo.

El debate y la recolocación de estos intelectuales en el escenario de la izquierda europea tuvieron una importante recepción por parte de los intelectuales que animaban Controversia... En efecto, no solo eran seguidos con atención sino que buena parte de las conclusiones de esos debates eran aceptadas. Así, lo mostró el primer número al publicar un artículo de Paramio y Reverte, donde estos caracterizaban a la crisis del marxismo europeo de la época, como sustancialmente diferente del que había protagonizado el revisionismo de principios de siglo de la mano de Bernstein. Desde la visión de los autores, compartida por los integrantes de la revista, se trataba de una crisis de época que sumía incluso a toda la cultura de izquierda, por lo que ya no se trataba sólo de revisar la teoría sino que afirmaban "ahora ésta entra en crisis, a causa de una crisis general de nuestra cultura y nuestros valores, crisis que afecta al marxismo como parte integrante de esa cultura" (PARAMIO y REVERTE: 1979, 07).

Acto seguido, los autores revalorizaban la experiencia del Eurocomunismo desarrollada al calor de la crítica a la intervención soviética en Checoslovaquia. Esta experiencia, decían, "supone la recuperación de la capacidad de intervención en la vida pública de los partidos (comunistas) occidentales" (Paramio y Reverte, 1979: 07, 08)y su acercamiento al centro de la escena política europea, haciendo inviable que la crisis general y la revolución, puedan seguir siendo las líneas estratégicas de la izquierda. Así, se instalaba la idea de que la salida a esa crisis general que afectaba a la izquierda sólo podía superarse mediante su integración a la sociedad capitalista, saliendo del aislamiento en que había permanecido el comunismo desde fines de la segunda guerra mundial. 
Para los intelectuales de izquierda exiliados en México, los desplazamientos del socialismo europeo contribuyeron a la lectura de la propia "derrota", a la asunción de la caducidad de la estrategia revolucionaria y la necesidad de que la izquierda apostara a una vía democrática ${ }^{23}$. En efecto, la recepción de las perspectivas teóricas críticas del marxismo, estuvo muy presente en la revisión que el grupo de Controversia...hizo de este paradigma. Marcó el derrotero por el cual estos intelectuales se fueron alejando de lo que concebían como un modelo "rígido", una guía pre constituida para decodificar el mundo social, buscando nuevas herramientas teóricas que pudieran aprehender la complejidad de la nueva realidad latinoamericana. En esa dirección se destacaba, como parte de un cambio más amplio, la idea de una explosión de nuevas ciudadanías de la mano de nuevos movimientos sociales, que en su emergencia rompían con los esquemas clasificatorios basados en las perspectivas clasistas y del tradicional sistema de partidos.

Así, ya tempranamente en el acta de constitución de la Mesa de Discusión Socialista se aseveraba que "el socialismo nunca se agotó históricamente en la doctrina de Marx" (ACTA DE CONSTITUCIÓN, 1980: 03), abriendo una puerta para la entrada de otras formas de pensar el ideario de izquierda. Es decir, posiciones intelectuales de izquierda que ponen en cuestión el canon del marxismo como la única y más apta guía teórica y política e incorporan nuevas referencias, algunas de ellas ajenas incluso a la tradición del socialismo.

\section{En busca Del tiempo perdido. Portantiero y El análisis del socialismo y la democracia}

Portantiero partió hacia México a fines de 1976 cuando "empiezan a picar los tiros cerquita" (MOCCA, 2012: 76) En efecto, por un lado, el allanamiento de la sede de la editorial siglo XXI junto a la detención de su titular Alberto Díaz que compartía la dirección nada menos que con Aricó, por otro, la detención de Jorge Tula animador de la revista Pasado y Presente sumado al modo azorado en que sus allegados lo miraban “dando vueltas” por Buenos Aires, lo llevo a tomar la determinación de marchar al exilio. Así recaló en el DF mexicano en momentos en que se inauguraba la sede de

\footnotetext{
${ }^{23}$ Cabe destacar que, por la misma época, se estaban dando desplazamientos similares en las izquierdas de otros países latinoamericanos. Por su cercanía y probable influencia en el proceso llevado adelante por los argentinos exiliados, fue importante la discusión que se dio dentro de la izquierda mexicanaque posibilitó un acercamiento del Partido Comunista Mexicano a los debates de los partidos del Eurocomunismo. Este viraje, que en el plano teórico implicó un acercamiento al pensamiento gramsciano, fue encarnado por el Partido Comunista Mexicano (PCM) y su sucesor, el Partido Socialista Unificado Mexicano (PSUM), creado en 1981, a partir de la disolución del primero. Burgos (2004: 233).
} 
FLACSO de esa ciudad ${ }^{24}$. Allí trabajaría en los mismos cargos que tuviera en Buenos Aires y en 1978, asumiría como director de la recientemente creada maestría en Ciencias Sociales.

Sus años mexicanos son años de ajuste de cuentas con el marxismo y en los que emprenderá sus teorizaciones sobre la democracia. Pero también los años en los que estudiaría filosofía política en cursos de FLACSO y el Colegio de México, entablaría un diálogo con la teoría política norteamericana y volvería sobre el pensamiento italiano pero esta vez para descubrir y apropiarse del pensamiento de Norberto Bobbio. Todo en el contexto que hemos descrito más arriba, un contexto donde la política y el campo intelectual sufrían profundos cambios.

\section{Marxismo, socialismo, democracia. Continuidades y rupturas}

Portantiero al igual que sus compañeros de ruta emprenderá un ajuste de cuentas con toda la etapa argentina de su trayectoria. Es en esa dirección que en su periplo mexicano acometió la tarea de examinar a las grandes tradiciones políticas pero haciendo foco de modo principal en la que él se había colocado, el marxismo. En esa revisión lo primero que Portantiero resaltaba era que tanto el cuerpo teórico clásico del marxismo como del liberalismo no podían atender a la complejidad de las sociedades de finales del siglo XX. Y así emprendía el examen del corpus teórico de Marx. Portantiero destaca en primer lugar que no hay allí una teoría positiva del Estado ya sea capitalista o de transición. Por ser un pensamiento fuertemente societalista que lleva al extremo la subsunción de lo político en lo social y así funda la base de una progresiva extinción del Estado con la recuperación de poderes alienados en aquel y que de este modo vuelven a la sociedad. Concepción propia de la tradición liberal que Marx radicaliza en términos democráticos. Para nuestro autor, el elemento anti estatalista es central en esa tradición y por eso su visión de la emancipación social tenía problemas para hacerse cargo de realidades como la nación y el Estado. En ese sentido es que Marx era para Portantiero un hombre del siglo XIX. Por eso no se hallaba en su obra magna El Capital, una teoría del Estado porque además de las restricciones que se había puesto al abordar su problema, Marx concebía que cuanto más débil fuera el Estado más libre era la

\footnotetext{
${ }^{24}$ Portantiero había coordinado con las autoridades de la facultad en Buenos Aires su traslado a la sede mexicana en momentos en que esta se inauguraba, hecho que le garantizó de entrada empleo pero también no tener grandes dificultades para su llegada y estadía (MOCCA, 2012) y entrevistas con el autor de 2005 .
} 
sociedad, esa era la visión que compartía con los liberales y que Marx llevaba a su extremo. Extremo que compartía con los anarquistas, puesto que la diferencia con estos se debía más a tiempos que a fines. El hecho de que la coacción sea transitoria y que esa transición sea teleológicamente definida de antemano, mostraba que en la concepción de Marx el pasaje del feudalismo al capitalismo es el modelo de su concepción de la transición futura.

Visión que Portantiero también encontrará como prolongación en Engels, específicamente en su texto De la Autoridad, donde sostiene que el Estado está condenado a desaparecer previa (lo mismo que en Marx) dictadura del proletariado para sentar las bases de una nueva sociedad, concepción que llega hasta Gramsci cuando postule como necesario un momento de "estadolatría" para acentuar la base cultural y moral necesaria de la nueva sociedad. Pero antes que en la reflexión de Gramsci, la cuestión de la dictadura y la extinción estatal aparece en Lenin también en El Estado y la Revolución. Así, de la tradición socialista sólo Lasalle que se inspiraba en el modelo Alemán colocará como dimensión problemática a la nación y el Estado, un modelo donde la nación es creada "desde arriba" poniendo de relieve el carácter per formatico del aparato estatal. Pero no solo por ser socialista el marxismo clásico desnudaba está falencia sino también porque en términos estratégicos políticos pregonaban la subordinación de las luchas nacionales al objetivo internacionalista.

Y nuevamente aseverará que en la crítica al programa de Gotha de Marx aparece claramente ésta perspectiva, visión societalista que, afirma lleva "implícita una imagen simple de las relaciones entre economía (clases) y política, condensada en su definición de 1848 sobre el Estado como comité administrativo de los intereses de la burguesía" (PORTANTIERO, 1980: 95). Para Portantiero esto era el producto del pensamiento de su tiempo, cuando funcionaba un liberalismo restringido que tuvo lugar hasta el último tercio del siglo XIX, donde los mecanismos políticos participativos se limitaban a escoger una selección de personal interno a la burguesía. De aquí que la especificidad de lo estatal perdía sentido puesto que durante todo ese ciclo que termina con la sanción del sufragio universal se establece una linealidad entre Estado y clase dominante. Así la especificidad de lo estatal frente a lo social perdía significación, de ahí que Portantiero lo entendiera "podía ser legítimo, por lo tanto, referirse a una etapa de transición (genérica) con una expresión también genérica como la de "dictadura del proletariado" (ídem). Por eso dirá que toda la discusión sobre el problema de la dictadura del proletariado que pierda de vista el contexto es una discusión bizantina. 
Lo que equivalía a sostener que ese pensamiento estaba datado pero por eso mismo en este caso estaba obsoleto. Pero además, Portantiero afirmaba que el modelo que estaba pensando Marx era el de la revolución francesa pero la cuestión consiste en que ese tipo de revolución burguesa fue una excepción histórica y de ningún modo una regla: Los procesos de transformación capitalista fueron en su mayoría revoluciones "desde arriba" [...] y lo mismo aconteció, luego de 1917, con las revoluciones socialistas (96). De ahí que para Portantiero Lasalle estaba más cerca de la realidad porque pensaba en el modelo Alemán, que desmentía las predicciones formuladas por Marx en 1848.

Quizás para que no se lo acusara de formular la explicación en términos simplistas y de tirar por la borda todo de una vez, Portantiero aclarará que Engels sí se hizo cargo de la nueva situación política en 1895, cuando ya se vislumbraba un Estado más complejo, en la introducción a la reedición de La lucha de clases en Francia. Pero su conclusión era también en este caso similar, dirá que al cabo no lo resolvería, y no lo hacía en tanto la formula especifica de la dictadura del proletariado estaba marcada por la experiencia de la comuna de París pero que él mismo señalaba en una carta a Bebel como obsoleto unos años después. Hasta allí llegará la reflexión de Engels, postulando el problema para luego seguir ceñido al antiguo modo de pensar. Y eso era por demás importante puesto que para que para nuestro autor, allí estaba la base de los problemas del marxismo de la II Internacional en su conjunto puesto que esa introducción se enfrentaba señala “[...] a las dos realidades más poderosas del siglo XX: el Estado y la nación" (96). Dado que las burguesías nacionales y las masas planteaban el problema de la lucha de clases en escenarios nacionales. Pero así como los derechos democráticos se ampliaban dirá que "el Estado burgués sufría transformaciones donde la participación podía ser neutralizada. Con el desplazamiento del poder hacia un centro de toma de decisiones gubernamental oligopólico en clave tecno burocrática poniendo en segundo plano, al parlamento donde se expresaba el sufragio universal” (ídem).

Esa concepción anti estatalista será una marca que funcionará como un fuerte legado puesto que también Lenin recogería la idea de transición, extinción y de ahí su antiparlamentarismo en la creencia de que los soviets (consejos) encarnaban mejor el proceso de transición. Los resultados históricos, sostiene Portantiero llevando el análisis ahora al terreno de la práctica, daban cuenta de que la profecía de la extinción en la URSS y en las que siguieron su modelo de dictadura del proletariado no resultó, por el contrario constituyeron un modelo de soberanía centrado en el partido vanguardia del 
proletariado. Todo el planteo y el centro de la cuestión se resumía en que en Marx la formula dictadura del proletariado no calificaba formas de gobierno dado su nivel de generalidad sino un tipo de Estado que podía expresarse de diversas maneras. En Lenin se traducía en que todo Estado es una dictadura de clases y expresa la naturaleza de la dominación pero no sus formas. Así, en los hechos esa caracterización tan amplía terminó debido a su generalidad "[...] por recuperar parte de su sentido tradicional, hasta transformarse en lo que finalmente fue: una forma autocrática de crear un ordenamiento jurídico, por la cual la ley y el poder descienden de arriba hacia abajo, pero no como procedimiento de excepción sino como forma permanente de gobierno" $(97,98)$.

De esa constatación histórica para Portantiero aparece como vacío discutir que quisieron decir Marx y Engels porque lo que importa dirá, es "cuál ha sido el resultado práctico de esa experiencia" (ídem). Y así cerraba en parte todo el problema. Porque dirá que en la medida en que la única herencia teórica disponible, sobre el tema del Estado (más allá de su crítica), eran las referencias generales a la dictadura del proletariado (que por añadidura Lenin consideraría como piedra de toque para diferenciar al verdadero marxismo), no es aventurado suponer que el enorme vacío que el marxismo del siglo XX propone sobre la cuestión se deriva de esa precaria contraposición entre un enunciado abstracto y una realidad estatal y social enormemente más compleja (95).

Todo ese examen y esa crítica llevaba la cuestión hacia un tema capital puesto que el problema no era solo el de que no podía hacerse un examen del Estado. Sino también que en esa idea genérica, que contenía un sentido teleológico de una transición hacia el fin del Estado no era posible pensar un orden político democrático equilibrado. Y esto máxime si al poder se lo concibe como una emanación de la sociedad y no una potencia autónoma porque ello impide ver las necesidades de equilibrar ese poder con otras instituciones, de ahí que deba plantearse la pregunta por el quién ejerce el poder pero también el cómo. A eso Lenin respondía, a través de los Soviet, pero el problema era que esa institución no ha tenido un peso significativo, sostiene nuestro autor, quedando relegado y su puesto lo ha ocupado el partido único que garantiza la ideología, que a su vez promueve la fragmentación social ya que no tolera ninguna iniciativa colectiva o individual por fuera del partido o del Estado. Así, la dictadura del proletariado niega toda forma de pluralismo y es un medio de enajenación política igual al que prima en las sociedades capitalistas. El resultado histórico entonces es una forma 
de la apatía como en la URSS o la aclamación plebiscitaria en los países subdesarrollados, que no resuelven lo esencial "porque lo esencial ya lo desarrollo la cúpula" $(100,101)$. Así, dirá que la dictadura del proletariado es un despotismo ilustrado que resuelve los satisfactores mínimos económicos, que por cierto Portantiero no subestima, pero que no garantizan incrementos de participación social y política. Y frente a eso, las insatisfacciones se manifiestan en forma de estallidos como en Polonia o en Praga en 1968. Ahora, frente a ese escenario, Portantiero admite que hubo dos respuestas una consejista (troskista) y otra que postula la idea de hegemonía. Para el primer caso, señala, aun con algunas ventajas como la postulación de la socialización del Estado y la recomposición de la disociación entre economía y política, el esquema adolece de limitaciones internas, la postulada democracia directa choca con el número de sus participantes. Pero más importantes es el hecho de que los consejos son el único órgano de representación de la soberanía y absorbe todas sus demandas destruyendo cualquier tipo de institución perdiendo así la noción de democracia. Por otro lado, al postular a la figura del productor como única forma de agregación política tiende así a una representación de tipo corporativa. En cambio hegemonía para Portantiero sí podía acercar posiciones entre socialismo y democracia, siempre y cuando la hegemonía reemplazara a la dictadura efectivamente, porque hegemonía advertirá, tiene tantos (o más) potencialidades totalitarias que dictadura, que estaban en el propio Gramsci, cuando este exaltaba a 'la hegemonía de forma 'orgánica' donde prima la homogeneidad y semejanza donde la sociedad hecha Estado premia a los valores de la integridad personal y sociocultural disolviendo la vida activa de la sociedad civil y encarna a una estructura que interpreta y responde a todas las demandas" (101).

Para Portantiero es claro que una recomposición de las particularidades es imprescindible y el problema se traslada a los modos de esa recomposición. Allí su solución la encarna una hegemonía pluralista, que ve en el consenso una realización que no disuelva las diferencias, que legitima los disensos y que articula la posibilidad de procesarlos, a través de un diseño institucional complejo que trata de procesar la democracia y la transición. Aquí es donde, para nuestro autor, deberá articularse el cómo y el quién de la democracia. Buscando un proceso de continuidad entre democracia formal y democracia sustantiva. En esa dirección sostenía que efectivamente para que la perspectiva sea realmente democrática es necesario que haya una tensión social hacia la igualdad de base y esta se incline hacia el desarrollo de procesos de transformación de las relaciones de producción, pero advertía mostrando 
donde estaba su desplazamiento, que esta es una condición necesaria pero no suficiente de la democracia. Puesto que

hay una autonomía de la problemática de la construcción de la democracia, que desborda la determinación mecánica por los modos de producción o de propiedad. La democracia es también necesariamente 'formal' y no podría ser de otra manera, pues remite a la construcción de un orden político [...] más allá de una determinación económica, democracia significa: participación de todos en la formación de las decisiones, lo que no puede resolverse por agregación corporativa sino a través de instituciones de tipo parlamentario, esto es surgida del sufragio universal. En segundo lugar. Democracia quiere decir posibilidad de control institucional (es decir, no asambleistico ni por aclamación) por parte de la sociedad sobre el estado. Y, por fin, libertad para disentir (PORTANTIERO, 1980:103).

En clave luxembuegueana Portantiero introducía preceptos liberales para exorcizar al marxismo de sus claves totalitarias. Consumaba así una operación que consistía primero, al igual que lo habían hecho los italianos, en demostrar cómo el marxismo dejaba un lugar vacío para pensar teóricamente la complejidad de la política y del Estado y por esa vía a la representación de la sociedad. En segundo lugar, buscaba mostrar como ese lugar vacío podía llevar a un régimen totalitario por la vía precisamente de la falta teórica y por ello también política para actuar en el curso de la realidad social.

Era esa mirada la consumación de su adiós al marxismo, éste ya no podía ser un prisma con el cual examinar la política. Pero era también en el mismo desplazamiento la entrada de la democracia política en su nueva perspectiva, entendida como la producción de un orden institucional. Lo que más le interesaba en ese sentido era el contrapeso que debía formarse en las instancias del control efectivo del poder. Lo que le importaba en esa dirección era cómo resolver la contradicción entre el centro estatal y la sociedad. El marxismo como ya vimos, a través de la extinción o de la representación en clave corporativa no dejaba lugar a una salida satisfactoria, en cambio el liberalismo, dirá, pensó esas cuestiones con mayor realismo. Aún cuando el ciudadano de la ciudad liberal existió para sociedades en donde la participación era restringida. Esos principios de constitución ciudadana eran lícitos ponerlos en práctica cuando esa ciudadanía se 
ampliaba. Esto es, cuando un ciudadano un voto ya no tenía sentido por ser el mundo del siglo XX un mundo de grupos y corporaciones. De ahí que afirmara que aunque la democracia no es identificable con el Estado liberal, el socialismo no debía prescindir de la acumulación cultural y política que implicaban ciertas adquisiciones del liberalismo.

Porque para Portantiero "a la teoría política del socialismo le ha sobrado Rousseau y le ha faltado Locke. Por ese exceso y por ese defecto le ha nacido la tentación por Hobbes" (104). La cita además de pintoresca consuma la recolocación que se produce en su pensamiento a principios de los años $80^{\prime}$.

Pero esa recolocación conllevaba además un trabajo de resignificación de la tradición socialista que hiciera posible articularla con la idea de democracia política. Así, Portantiero va a integrar el grupo de los que más se inclinaron por desmontar la imagen clásica de la democracia asociada de modo automático al ideario liberal. Sus operaciones conceptuales van a buscar, lo mismo que muchos de los exiliados que reseñamos más arriba, re posicionar de otro modo el status de la democracia para el ideario socialista. En esa dirección en un artículo publicado en Controversia en 1981 sostenía que si bien la identificación entre democracia y liberalismo (y, por esa vía, entre democracia y capitalismo) suele aparecer como un dato no cuestionado tanto para los mismos liberales como para parte de las izquierdas:

sea la socialdemocracia [...] sean aquellos que, con el calificativo de burguesa, niegan toda raigambre popular al concepto de democracia y lo relegan como un capítulo de la historia de las clases dominantes [...] las cosas fueron diferentes; la democracia no es un dato que necesariamente surge de una estructura sino que es una producción social. Ni la democracia formal es co extensa con el capitalismo, ni la estatización de los medios de producción genera automáticamente a la 'verdadera democracia'; la democracia es, por el contrario, una construcción popular (PORTANTIERO, 1981: 04).

En esta lectura, la democracia no aparece ya como una concesión de las clases dominantes a las clases dominadas ni tampoco, otra lectura clásica del marxismo, como "máscara" que encubre la desigualdad de clase. También aquí desmonta la asociación de marxismo y democracia. Como se recordará, para el espectro marxista el socialismo implicaba necesariamente la consumación de la democracia en tanto ésta estaba 
garantizada por la igualdad de los productores que eran ahora dueños de los medios de producción. Pero en lo que refiere al primer aspecto, sugiere que esto no es así porque el capitalismo “[...] no necesita de la democracia [...]”; éste sólo requiere de bases jurídicas que garanticen el libre comercio y el trabajo libre, de ahí que "todo el resto: valores e instituciones que se asocian con la democracia [...] configuran conquistas políticas e ideológicas arrancadas a través de las luchas populares" (6). La lucha democrática entonces era parte de la lucha popular, de una lucha nacional popular y en ese sentido podía adquirir un nuevo status en el ideario socialista.

Por eso la contestación de la derrota teórica y políticamente mostraba a la democracia como la única salida posible para la encerrona. Pero en ese movimiento aparece de manera sutil no solo la idea de que habían sido derrotados sino también que habían estado equivocados. Y aquí es donde, como vimos, las referencias externas, los diálogos con la tradición de la izquierda europea pero más importante aún, la italiana, cobran una dimensión central. Es que, en efecto, qué hubiera pasado de no producirse "la crisis del marxismo" en ese centro de referencia ineludible que fue siempre para Portantiero la izquierda italiana? No lo sabemos pero seguramente estaríamos contando otra historia. Es que los diálogos en las tradiciones políticas e intelectuales entre centro y periferia son un mirador privilegiado para la explicación del mundo intelectual. Esos diálogos con sus apropiaciones y formas particulares de procesar los temas signan momentos importantes del mundo intelectual. Momentos de pasajes, de rupturas y reacomodamientos de las trayectorias y los modos de pensar. Como sea, el exilio mexicano en la trayectoria de Portantiero, consumaba de ese modo el primer paso para saldar cuentas con sus años 60', para cerrar ese capítulo y para inaugurar lo que de variadas formas lo acompañará hasta su muerte.

\section{Fuentes}

\section{Entrevistas}

Lucas Rubinich.

Carlos Altamirano.

Juan Carlos Portantiero.

Osvaldo Pedroso.

Sergio Bufano.

Jorge Tula.

Maria Alicia Gutierrez.

Ernesto Filippi. 
Gastón Burucua.

\section{Referencias bibliográficas}

ACHA, Omar (2006). La nación futura. Rodolfo Puiggrós en las encrucijadas argentinas del Siglo XX. Buenos Aires: Eudeba.

ALTAMIRANO, Carlos (2005). Ideas para un programa de historial intelectual. En Para un programa de historia intelectual y otros ensayos. Buenos Aires. Siglo XXI editores.

ALTAMIRANO, Carlos (2006). Intelectuales. Notas de investigación. Buenos Aires. Norma Grupo Editorial.

ALTAMIRANO, Carlos (Director) (2008). Historia de los intelectuales en América Latina. Dos volúmenes. Buenos Aires. Katz.

ANDERSON, P. (2004). Tras las huellas del materialismo histórico. Buenos Aires: Siglo XXI editores.

ARICÓ, J. M. (1980). Marx y América Latina. Lima. Fondo de Cultura Económica. (1988). La cola del diablo. Itinerario de Gramsci en América Latina. Buenos Aires. Punto Sur.

(1963). Pasado y Presente. Pasado y Presente, Córdoba, s/d, número 1, (pp. 2-4) .(1980). Advertencia. En Weber, Max. Escritos Políticos. México. Editorial. Folios.

BASUALDO, Victoria. (2006). La participación de los trabajadores y sindicalistas en la campaña internacional contra la última dictadura argentina. Sociedad, 25. (2007). Una aproximación al exilio obrero y sindical. En YANKELEVICH, P. \& JENSEN, S. (Comp.) Exilios. Destinos y experiencias bajo la dictadura militar. Buenos Aires: Libros del Zorzal.

BLANCO, Alejandro (2008). Encuesta sobre el concepto de recepción, respuesta de Alejandro Blanco.Políticas de la Memoria. Número 8/9. Primavera 2008. Buenos Aires.

BERNETTI, J. L. y GIARDINELLI, M. (2003). México: El exilio que hemos vivido. Memoria del exilio argentino en México durante la dictadura 1976-1983. Buenos Aires. Universidad Nacional.

BOURDIEU, Pierre (1998). Campo intelectual, campo de poder, Buenos Aires. Taurus. Ediciones (2000). Las condiciones sociales de la circulación de las ideas. En Intelectuales, Política y Poder. Buenos Aires. Eudeba. .(2000). El campo intelectual: un mundo aparte. En Cosas Dicha. Barcelona.Gedisa.

BURGOS, Raúl (2004) Los gramscianos argentinos. Cultura y política en la experiencia de Pasado y Presente.Buenos Aires. Siglo XXI editores.

CARNOVALE, Vera (2014).El PRT-ERP en el exilio. Armas, comunismo y derechos humanos. Revista de Historia Facultad de Humanidades Universidad Nacional del Comahue.

CASCO, José (2008). El exilio intelectual en México. Notas sobre la experiencia argentina (1974 1983). Apuntes de investigación del CECYP. Año XII Numero 13.

(2017). De la revolución a la democracia. 40 años de cultura y política en la obra de Juan Carlos Portantiero. Tesis doctoral. Mimeo. 
CASTAÑEDA, J. (1989). De cara al mundo la política exterior mexicana. México: Planeta.

CONFINO,Hernán ( 2018).Entre la articulación y el conflicto: Una aproximación a los itinerarios de los exiliados montoneros en México. En Exilios: Un campo de estudios en expansión. Lastra (Comp) CLACSO.

(2019). Exilio, debate y ruptura. Los balances de la Contraofensiva montonera de 1979 y la constitución de "Montoneros 17 de octubre". Anuario de la Escuela de Historia Universidad Nacional de Rosario.

COSER, L. (1968). Hombres de Ideas. El punto de vista de un sociólogo. Buenos Aires. Fondo de Cultura Económica.

DE DIEGO, José Luis (2003). ¿Quién de nosotros escribirá el Facundo? Intelectuales y escritores en Argentina (1970-1986). La Plata. Ediciones Al Margen.

.(2010). Los intelectuales y la izquierda en Argentina (1955 1975). En Historia de los intelectuales en América Latina. Vol II. Buenos Aires.

DEL BARCO, O. (1980). Esbozo de una crítica a la teoría y práctica leninista. Puebla. UNAM.

DEVÉS VALDÉS, E. (2003). El pensamiento Latinoamericano en el siglo XX. Tomo II. Buenos Aires. Biblos.

DOSSE, F. (2006). La marcha de las ideas. Historia de los intelectuales. Historia intelectual. Valencia. Publicaciones de la Universidad de Valencia.

ELIZALDE, Josefina (2009). Intelectuales y política en la transición democrática. El grupo Esmeralda. Tesis de Maestría. FLACSO. Mimeo.

FLISFICH, Ángèl. (1981). El surgimiento de una nueva ideología democrática en América Latina.Crítica y Utopía. Número 8.

GAGO, Verónica (2012). Controversia: Una lengua del exilio. Buenos Aires. Ediciones de la Biblioteca Nacional.

GARATEGARAY, Martina (2013). Democracia, intelectuales y política. "Punto de Vista, Unidos y La Ciudad Futura" en la transición política e ideológica de la década del '80". Revista Estudios, número 29, enero-junio CEA-UNC.

GORDILLO, Mónica (2003). Protesta, rebelión y movilización: de la resistencia a la lucha armada, 1955-1973. En: James, Daniel, ed. Nueva Historia Argentina. Tomo IX: Violencia, proscripción y autoritarismo (1955-1976). Buenos Aires: Sudamericana.

HOFMEISTER, W. y MANSILLA. H. C. F. (Eds.) (2003). Intelectuales y política en América Latina. El desencantamiento del espíritu crítico. Santa Fe. Politeia.

JAMES, Daniel (2010). Resistencia e Integración. El peronismo y la clase trabajadora argentina. 1946-1976. Buenos Aires. Sudamericana.

(ed) (2007). Nueva Historia Argentina. Tomo IX: Violencia, proscripción y autoritarismo (1955-1976). Buenos Aires: Sudamericana.

LABASTIDA, Julio (1985). Hegemonía y alternativas políticas en América Latina. México. Siglo XXI editores.

LECHNER, Norbert (1986). De la revolución a la democracia. El debate intelectual en América del Sur. La Ciudad Futura. Revista de Cultura Socialista Número 2. .(ed.) (1982). ¿Qué significa hacer política? Lima: FLACSO.

LESGART, Cecilia (2003). Usos de la transición a la democracia. Ensayo, ciencia y política en la década del 80 '. Santa Fe. Politeia.

MANHEIM, Karl. (1963). Ensayos sobre sociología de la cultura. Buenos Aires. Fondo de Cultura Económica. 
MARGULIS, Mario (1986). Los argentinos en México. En Alfredo Lattes y Enrique Oteiza (Coords.). Dinamica migratoria Argentina (1955-1984) Democratización y retorno de expatriados. Buenos Aires, CEAL, vol. 1.

MARRAMAO, G. et al. (1981). La crisis del capitalismo en los años '20. Análisis económico y debate estratégico en la tercera internacional. México. Ediciones Pasado y Presente.

Mocca Edgardo. (2012). Juan Carlos Portantiero: Un itinerario político-intelectual. Buenos Aires. Ediciones de la Biblioteca Nacional.

MONTAÑA, Jimena (2014). Algunas consideraciones sobre el estudio de grupos intelectuales y proyectos políticos-culturales colectivos. El caso de la revista La Ciudad Futura. (1986-1998). En El IV Taller de Historia Intelectual. Córdoba.

NUN, José; PORTANTIERO, Juan Carlos (Comps.) (1987). Ensayos sobre la transición democrática en la Argentina Buenos Aires. Puntosur.

O’DONNELL, G., SCMITTER, P. y WHITEHEAD, L. (Comps.)(1989). Transiciones desde un gobierno autoritario. Buenos Aires. Editorial Paidós.

ORY, Pascal (1990). ¿Qué es un intelectual? En $A A V V$. Madrid Alianza.

PALTI, Elias. (2005). Verdades y saberes del marxismo. Reacciones de una tradición política ante su "crisis". Buenos Aires. Fondo de Cultura Económica.

PARAMIO, L. (1987). Tras el diluvio; La izquierda ante el fin de siglo. España. Siglo XXI editores.

PATIÑO, R. (s/f). Culturas en transición. Reforma ideológica, democratización yperiodismo cultural en la Argentina de los ochenta. Disponible en: http:// w.w.w.iacd.oas.org.

POGGI, Gianfranco (1979). Encuentro con Max Weber. Buenos Aires. Nueva Visión. .(1978). El desarrollo del Estado moderno. Buenos Aires. Universidad Nacional de Quilmes.

PONZA, Pablo (2013). El club de Cultura Socialista y la gestión Alfonsìn: Transiciòn a una nueva cultura plural y democrática. Nuevo Mundo, Mundos Nuevos. https://nuevomundo.revues.org.

.(2013b). Juan Carlos Portantiero: democracia a treinta años de la transición. Revista Pàginas. Vol 5. Rosario

PORTANTIERO, Juan Carlos (1979). La democracia difícil, proyecto democrático y movimiento popular. Controversia. Para el análisis de la realidad argentina. Número 1.

.(1979). Transformación social y crisis de la política. Controversia. Para el análisis de la realidad argentina. Número 2.

.(1980). Los dilemas del socialismo. Controversia. Para un análisis de la realidad argentina. Número 3.

.y DE ÍPOLA, Emilio (1980). Lo nacional-popular y los populismos realmente existentes. Controversia. Para un análisis de la realidad argentina. Número 6.

(1981). Socialismo y política en América Latina. En Estado y política en América Latina. (comp.), Lechner, Norbert México. Siglo XXI editores.

(1988). La producción de un orden. Ensayos sobre la democracia entre el estado y la sociedad. Buenos Aires: Nueva Visión.

.(1996). Economía y Política en la crisis argentina. 1958-1973. En Ansaldi, Waldo y Moreno, José Luis (Eds.). Estado y sociedad en el pensamiento nacional. Antología conceptual para el análisis comparado. Argentina. Cántaro. .(1999). Los usos de Gramsci. Buenos Aires: Grijalbo. 
REANO, Ariana (2012). Controversia y La ciudad Futura: Democracia y socialismo en debate. Revista Mexicana de Sociología. Año 74, Numero 3. Julio Septiembre. México. UNAM.

SIGAL, Silvia, (2002). Intelectuales y poder en la Argentina. La década del sesenta. Buenos Aires.Siglo XXI editores.

SOARES ARROSA, María Susana (2003). Un nuevo escenario anticapitalista. Entrevista a Aníbal Quijano. En Intelectuales latinoamericanos ayer y hoy. Santa Fe: Politeia.

TARCUS, Horacio (2007). Diccionario biográfico de la izquierda argentina. Buenos Aires. Emece.

TERÁN, Oscar (Coord) (2005). Ideas en el siglo. Intelectuales y cultura en el siglo XX latinoamericano.Buenos Aires. Siglo XXI editores.

TORTTI, M. C y CHAMA, M. (2006). Los nudos políticos e Intelectuales de una trayectoria. Entrevista a Juan Carlos Portantiero. Cuestiones de sociología. Revista de Estudios Sociales. Buenos Aires. Prometeo Libros.

TRÍMBOLI, J. (1988). La izquierda en Argentina. Buenos Aires. Manantial.

WILLIAMS, R. (2000). 1977. Marxismo y literatura.Barcelona: Península.

YANKELEVICH, P. (Coord.) (2002). México, País refugio: La experiencia de los exilios en el siglo XX. México: INAH y Plaza y Valdés. (2004). Represión y destierro. Itinerarios del exilio argentino. Buenos Aires. Editorial Al Margen.

y JENSEN. S. (2007). Exilios. Destinos y experiencias bajo la dictadura militar. Buenos Aires. Libros del Zorzal. .(2009). Ráfagas de un exilio: argentinos en México, 1974-1983. Buenos Aires. Fondo de Cultura Económica.

Artigo recebido em20 de agosto de 2019.

Aprovado em 27 de novembro de 2019.

DOI:10.12957/intellectus.2019.44702 